\title{
Sustained high serum caspase-3 concentrations and mortality in septic patients
}

\author{
L. Lorente ${ }^{1}$ (1) - M. M. Martín ${ }^{2}$ A. Pérez-Cejas ${ }^{3} \cdot$ A. F. González-Rivero ${ }^{3} \cdot$ R. O. López ${ }^{4}$. \\ J. Ferreres $^{5}$ • J. Solé-Violán ${ }^{6}$ - L. Labarta ${ }^{7}$ - C. Díaz ${ }^{8} \cdot$ S. Palmero ${ }^{9}$ - A. Jiménez ${ }^{10}$
}

Received: 25 September 2017 / Accepted: 26 October 2017

(C) Springer-Verlag GmbH Germany 2017

\begin{abstract}
Caspase-3 is the main executor of the apoptotic process. Higher serum caspase- 3 concentrations in nonsurvivor compared to survivor septic patients have been found. The objectives of this work (with the increase of sample size to 308 patients, and the determination of serum caspase- 3 concentrations also on days 4 and 8 of diagnosis of severe sepsis) were to know whether an association between serum caspase- 3 concentrationss during the first week, degree of apoptosis, sepsis severity, and sepsis mortality exists. We collected serum samples of 308 patients with severe
\end{abstract}

L. Lorente

lorentemartin@msn.com

M. M. Martín

mar.martinvelasco@gmail.com

\section{A. Pérez-Cejas \\ aperezcejas@gmail.com}

\author{
A. F. González-Rivero \\ agonriv@hotmail.com \\ R. O. López \\ raorlo@gmail.com \\ J. Ferreres \\ ferreresj@gmail.com \\ J. Solé-Violán \\ jsolvio@gobiernodecanarias.org \\ L. Labarta \\ 1labarta@salud.aragon.es \\ C. Díaz \\ incaicos@yahoo.es \\ S. Palmero \\ salome.palmero@gmail.com
}

sepsis from eight intensive care units on days 1,4 and 8 to measure concentrations of caspase- 3 and caspase-cleaved cytokeratin (CCCK)-18 (to assess degree of apoptosis). End point was 30-day mortality. We found higher serum concentrations of caspase-3 and CCCK-18 in non-survivors compared to survivors on days 1 ( $\mathrm{p}<0.001), 4(\mathrm{p}<0.001)$, and $8(\mathrm{p}<0.001)$. We found an association between serum caspase- 3 concentrations on days 1,4 and 8 of severe sepsis diagnosis and serum CCCK-18 concentrations $(\mathrm{p}<0.001)$, SOFA $(\mathrm{p}<0.001)$, serum acid lactic concentrations
A. Jiménez
ajimenezsosa@gmail.com

1 Intensive Care Unit, Hospital Universitario de Canarias, Ofra, s/n. La Laguna, 38320 Tenerife, Spain

2 Intensive Care Unit, Hospital Universitario Nuestra Señora Candelaria, Crta Rosario s/n, 38010 Santa Cruz Tenerife, Spain

3 Laboratory Department, Hospital Universitario de Canarias, Ofra, s/n. La Laguna, 38320 Tenerife, Spain

4 Intensive Care Unit, Hospital General de La Palma, Buenavista de Arriba s/n, 38713 Breña Alta, La Palma, Spain

5 Intensive Care Unit, Hospital Clínico Universitario de Valencia, Avda. Blasco Ibáñez n¹7-19, 46004 Valencia, Spain

6 Intensive Care Unit, Hospital Universitario Dr. Negrín, Barranco de la Ballena s/n, 35010 Las Palmas de Gran Canaria, Spain

7 Intensive Care Unit, Hospital San Jorge de Huesca, Avenida Martínez de Velasco n³6, 22004 Huesca, Spain

8 Intensive Care Unit, Hospital Insular, Plaza Dr. Pasteur s/n, 35016 Las Palmas de Gran Canaria, Spain

9 Intensive Care Unit, Hospital Quirón Tenerife, Poeta Rodriguez Herrera $n^{\circ} 1,38006$ Santa Cruz de Tenerife, Spain

10 Research Unit, Hospital Universitario de Canarias, Ofra, s/n. La Laguna, 38320 Tenerife, Spain 
( $p<0.001)$, and 30-day sepsis mortality $(p<0.001)$. The new findings of this work were that an association between serum caspase- 3 concentrations during the first week, apoptosis degree, sepsis severity, and sepsis mortality exists.

\section{Introduction}

Severe sepsis leads to burden of health resources and many deaths annually $[1,2]$. Cell death by apoptosis occurs during sepsis. Apoptosis is initiated mainly through two pathways, by death receptors (or extrinsic pathways) or by mitochondrial contribution (or intrinsic pathways). In both pathways, caspase-3 is activated and leads to cell death [3-6].

An increase of caspase- 3 activity in different body sites in septic animal models has been found [7-18]. Besides, higher caspase-3 activity has been found in lymphocytes of septic patients compared to healthy controls [19-21], in spleen samples of septic patients (post mortem obtained) comparted to nonseptic patients (obtained from emergent splenectomy due to bleeding) [22], and in plasma of septic patients compared to non-septic patients [23]. In addition, another study found higher serum caspase- 3 levels over $72 \mathrm{~h}$ in septic patients with decreased lactate clearance, and higher mortality rate in those patients with lower lactate clearance [24]. In addition, we previously determined serum caspase- 3 concentrations in 216 severe septic patients at the time of diagnosis [25], and an association between serum caspase-3 concentrations and 30-day mortality was found. The objectives of this work (with the increase of sample size to 308 patients, and the determination of serum caspase- 3 concentrations also on days 4 and 8 of diagnosis of severe sepsis) were to know whether an association between serum caspase- 3 concentrations during the first week, degree of apoptosis, sepsis severity, and sepsis mortality exists. If those associations were found, then serum caspase- 3 concentration determination could be proposed to estimate the prognosis of those patients, and could open interest for research about agents that modulate caspase- 3 activation in those patients.

\section{Methods}

This was a multicenter study carried out with 308 severe septic patients of intensive care units from eight Spanish hospitals: $\mathrm{H}$ General de La Palma (La Palma), HU Insular (Las Palmas de Gran Canaria), H Quirón (Santa Cruz de Tenerife), HU de Valencia (Valencia), HU de Canarias (La Laguna), H San Jorge (Huesca), HU Dr. Negrín (Las Palmas de Gran Canaria), and HU Nuestra Señora de Candelaria (Santa Cruz de Tenerife). Ethic review boards from each hospital approved the project. Patients or their legal guardians signed the informed consent.

We included patients with severe sepsis on the basis of the International Sepsis Definitions Conference [26]. We excluded patients with human immunodeficiency virus (HIV), white blood cell count $<1000 / \mu \mathrm{L}$, solid or hematological tumor, steroid, immunosuppressive or radiation therapy, pregnancy, lactation or age $<18$ years.

Previously, we determined other circulating biomarkers in some of those patients [27-31]. In a previous work, we analyzed serum caspase- 3 concentrations in 216 severe septic patients at the time of diagnosis [25]. In this work, we determined serum caspase- 3 concentrations also on days 4 and 8 of diagnosis of severe sepsis in 308 patients.

The following variables were collected: age, acute physiology and chronic health evaluation II (APACHE II) score [32], activated partial thromboplastin time (aPTT), bloodstream infection, bilirubin, caspase-3, caspase-cleaved cytokeratin (CCCK)-18, chronic renal failure (defined as glomerular filtration rate $<60 \mathrm{ml} / \mathrm{min} / 1.73 \mathrm{~m}^{2}$ ), chronic obstructive pulmonary disease (COPD), diabetes mellitus, creatinine, empiric antimicrobial treatment, international normalized ratio (INR), lactic acid, ischemic heart disease, leukocytes, microorganism responsible, pressure of arterial oxygen/fraction inspired of oxygen $\left(\mathrm{PaO}_{2} / \mathrm{FIO}_{2}\right)$, platelets, sepsis-related organ failure assessment [SOFA] score [33], site of infection, and sex. We considered mortality at 30 days as the end point.

Serum blood samples at days 1,4 and 8 were taken to measure concentrations of caspase- 3 and CCCK-18 serum levels, and were stored at $-80{ }^{\circ} \mathrm{C}$ until the determination moment in the Laboratory Department of the Hospital Universitario de Canarias (La Laguna, Tenerife, Spain). Enzyme-linked immunosorbent assay (ELISA) assays were used to measure caspase- 3 with Human Caspase 3 Elisa BlueGene Biotech ${ }^{\circledR}$ kit (Shanghai, China) and CCCK-18 with M30 Apoptosense ${ }^{\circledR}$ ELISA, PEVIVA AB kit (Bromma, Sweden). For caspase-3, the intra- and inter-assay coefficients of variation $(\mathrm{CV})$ were $<5.6 \%$ and $<7.9 \%$, respectively, and the detection limit was $0.1 \mathrm{ng} / \mathrm{mL}$. For CCCK-18, the intra- and inter-assay CV were $<10 \%$, and the detection limit was 25 U/L. Serum concentrations of CCCK-18 levels were determined to assess degree of apoptosis [27, 34-36].

We used frequencies (and percentages) and chi-square test to report and compare categorical variables, and medians (and interquartile ranges) and Mann-Whitney $U$ test to report and compare continuous variables. Receiver operating characteristic (ROC) analyses with serum concentrations of caspase3 at days 1, 4 and 8 , and survival at 30 days were carried out; and we used the Youden $\mathrm{J}$ index to select the prognostic cutoff value for each day. Kaplan-Meier 30-day survival curves using cut-off values of serum caspase- 3 concentrations (selected according to Youden $\mathrm{J}$ index) of $0.22 \mathrm{ng} / \mathrm{mL}$ on day $1,0.16 \mathrm{ng} / \mathrm{mL}$ on day 4 , and $0.14 \mathrm{ng} / \mathrm{mL}$ on day 8 were carried out. Logistic regression analyses were carried out to determine whether an association between 30-day mortality and serum concentrations of caspase- 3 on days 1,4 and 8 exists. 
Table 1 Baseline clinical and biochemical characteristics of survivor and non-survivor patients

\begin{tabular}{|c|c|c|c|}
\hline Characteristic & $\begin{array}{l}\text { Survivors } \\
(\mathrm{N}=206)\end{array}$ & $\begin{array}{l}\text { Non-survivors } \\
(\mathrm{N}=102)\end{array}$ & $\begin{array}{l}\text { P- } \\
\text { value }\end{array}$ \\
\hline Age, median years (p 25-75) & $60(47-69)$ & $65(55-74)$ & 0.003 \\
\hline APACHE-II score, median (p 25-75) & $19(15-23)$ & $24(19-29)$ & $<0.001$ \\
\hline aPTT, median seconds (p 25-75) & $32(28-39)$ & $36(29-45)$ & 0.01 \\
\hline Bilirubin (mg/dl), median (p 25-75) & $0.88(0.50-1.40)$ & $0.97(0.50-2.33)$ & 0.22 \\
\hline Bloodstream infection, $\mathrm{n}(\%)$ & $28(13.6)$ & $16(15.7)$ & 0.61 \\
\hline Caspase-3, median ng/mL (p 25-75) & $0.12(0.10-0.23)$ & $0.41(0.23-0.49)$ & $<0.001$ \\
\hline CCCK-18, median u/L (p 25-75) & $299(242-398)$ & $474(326-694)$ & $<0.001$ \\
\hline Chronic renal failure, $\mathrm{n}(\%)$ & $12(5.8)$ & $13(12.7)$ & 0.046 \\
\hline COPD, n $(\%)$ & $28(13.6)$ & $11(10.8)$ & 0.59 \\
\hline Creatinine (mg/dl), median (p 25-75) & $1.30(0.80-2.10)$ & $1.66(1.00-2.80)$ & 0.01 \\
\hline Diabetes Mellitus, n (\%) & $51(24.8)$ & $40(39.2)$ & 0.01 \\
\hline Empiric antimicrobial treatment adequate & & & 0.64 \\
\hline Unknown due to negative cultures, $\mathrm{n}(\%)$ & $105(51.0)$ & $55(53.9)$ & \\
\hline Unknown due to diagnosis by antigenuria, $\mathrm{n}(\%)$ & $15(7.3)$ & $4(3.9)$ & \\
\hline Adequate, $\mathrm{n}(\%)$ & $82(39.8)$ & $40(39.2)$ & \\
\hline Inadequate, $\mathrm{n}(\%)$ & $4(1.9)$ & $3(2.9)$ & \\
\hline INR, median (p 25-75) & $1.25(1.10-1.50)$ & $1.42(1.15-1.91)$ & 0.004 \\
\hline Ischemic heart disease, $\mathrm{n}(\%)$ & $20(9.7)$ & $11(10.8)$ & 0.84 \\
\hline \multicolumn{4}{|l|}{ Microorganism responsible } \\
\hline Unknown, n (\%) & $105(51.0)$ & $55(53.9)$ & 0.63 \\
\hline Gram-positive, n (\%) & $52(25.2)$ & $24(23.5)$ & 0.78 \\
\hline Gram-negative, n (\%) & $49(23.8)$ & $23(22.5)$ & 0.89 \\
\hline Fungi, $\mathrm{n}(\%)$ & $4(1.9)$ & $4(3.9)$ & 0.45 \\
\hline Anaerobe, n (\%) & $2(1.0)$ & $1(1.0)$ & 0.99 \\
\hline Lactic acid, median mmol/L (p 25-75) & $2.00(1.10-3.50)$ & $3.40(1.60-6.00)$ & $<0.001$ \\
\hline Leukocytes, median $\times 10^{3} / \mathrm{mm}^{3}(\mathrm{p} 25-75)$ & $14.2(9.2-18.9)$ & $15.0(7.1-20.6)$ & 0.96 \\
\hline $\mathrm{PaO}_{2} / \mathrm{FIO}_{2}$ ratio, median (p 25-75) & $180(123-271)$ & $170(104-240)$ & 0.17 \\
\hline Platelets, median $\times 10^{3} / \mathrm{mm}^{3}(\mathrm{p} 25-75)$ & $197(130-270)$ & $129(61-227)$ & $<0.001$ \\
\hline Sex & & & 0.52 \\
\hline Female, n (\%) & $67(32.5)$ & $37(36.3)$ & \\
\hline Male, n (\%) & $139(67.5)$ & $65(63.7)$ & \\
\hline Site of infection & & & 0.95 \\
\hline Respiratory, n (\%) & $119(57.8)$ & $57(55.9)$ & \\
\hline Abdominal, n (\%) & $55(26.7)$ & $28(27.5)$ & \\
\hline Urinary, n (\%) & $12(5.8)$ & $5(4.9)$ & \\
\hline Skin, n $(\%)$ & $9(4.4)$ & $5(4.9)$ & \\
\hline Endocarditis, n (\%) & $6(2.9)$ & $5(4.9)$ & \\
\hline Arthritis, $\mathrm{n}(\%)$ & $1(0.5)$ & $1(1.0)$ & \\
\hline CNS, n (\%) & $4(1.9)$ & $1(1.0)$ & \\
\hline Sodium, median mEq/L (p 25-75) & $138(134-142)$ & $137(133-142)$ & 0.35 \\
\hline SOFA score, median (p 25-75) & $9(7-11)$ & $11(9-14)$ & $<0.001$ \\
\hline Source of sepsis, n (\%) & & & 0.59 \\
\hline Community, n (\%) & $160(77.7)$ & $78(76.5)$ & \\
\hline Nosocomial extra-UCI, n (\%) & $23(11.2)$ & $15(14.7)$ & \\
\hline Nosocomial intra-UCI, n (\%) & $23(11.2)$ & $9(8.8)$ & \\
\hline
\end{tabular}

APACHE II acute physiology and chronic health evaluation, aPTT activated partial thromboplastin time, $C C C K$ caspase-cleaved cytokeratin, $C O P D$ chronic obstructive pulmonary disease, INR international normalized ratio, $\mathrm{PaO}_{2} / \mathrm{FIO}_{2}$ pressure of arterial oxygen/fraction inspired oxygen, $\mathrm{CNS}$ central nervous system, SOFA sepsisrelated organ failure assessment score 
We used Spearman's rank coefficient to test the correlation between serum concentrations of caspase-3, CCCK-18, and acid lactic, and SOFA score at days 1, 4 and 8 . $P$-values $<0.05$ were considered statistically significant, and Bonferroni correction was applied in multiple comparisons. We carried out statistical analyses by NCSS 2000 (Kaysville, UT, USA) and SPSS 17.0 (SPSS Inc., Chicago, IL, USA).

\section{Results}

Demographic and clinical characteristics in non-survivor $(n=102)$ and survivor patients $(n=206)$ are shown and compared in Table 1. Statistically significant differences between non-survivor and survivor patients were not found on $\mathrm{PaO}_{2} / \mathrm{FIO}_{2}$ ratio, leukocytes, bilirubin, sex, ischemic heart disease, COPD, bloodstream infection, site of infection, and microorganism responsible for sepsis. However, we found that non-survivors in comparison to survivors had higher rate of diabetes mellitus and chronic renal failure, and lower platelet count. In addition, non-survivors had higher lactic acid, age, INR, aPTT, SOFA score, creatinine, APACHE-II score, serum caspase- 3 concentrations, and serum CCCK-18 concentrations. Besides, non-survivors compared to survivors had higher serum concentrations of caspase 3 (Fig. 1) on day 1 $(\mathrm{p}<0.001)$, day $4(\mathrm{p}<0.001)$, and day $8(\mathrm{p}<0.001)$.

Correlations between serum concentrations of caspase 3 , CCCK-18 and acid lactic, and SOFA score during the first
Table 2 Correlations between serum levels of caspase-3, CCCK-18 and lactic acid, and SOFA score during the first week of severe sepsis

\begin{tabular}{llll}
\hline Measured variable & Day 1 & Day 4 & Day 8 \\
\hline CCCK-18 $(\mathrm{u} / \mathrm{L})$ & $r=0.37$ & $r=0.25$ & $r=0.30$ \\
& $\mathrm{P}<0.001$ & $\mathrm{P}<0.001$ & $\mathrm{P}<0.001$ \\
Acid lactic (mmol/L) & $r=0.26$ & $\mathrm{r}=0.25$ & $r=0.22$ \\
& $\mathrm{P}<0.001$ & $\mathrm{P}<0.001$ & $\mathrm{P}<0.001$ \\
SOFA score & $r=0.20$ & $r=0.21$ & $\mathrm{r}=0.30$ \\
& $P<0.001$ & $\mathrm{P}<0.001$ & $\mathrm{P}<0.001$ \\
\hline
\end{tabular}

CCCK caspase-cleaved cytokeratin, SOFA sepsis-related organ failure assessment score

P-values $<0.005$ are statistically significant after Bonferroni correction

week are shown in Table 2 . We found a statistically significant positive association of serum concentrations of caspase 3 with serum concentrations of CCCK-18 $(\mathrm{p}<0.001)$ and acid lactic $(\mathrm{p}<0.001)$, and with SOFA score $(\mathrm{p}<0.001)$ during the first week.

ROC analyses of serum concentrations of caspase- 3 on days 1,4 and 8 as well as 30-day mortality prediction are shown in Table 3 and Fig. 2. We found that serum concentrations of caspase- 3 on day $1(\mathrm{p}<0.001)$, day $4(\mathrm{p}<0.001)$, and day $8(\mathrm{p}<0.001)$ predict 30 -day mortality.

Logistic regression analyses are shown in Table 4. We found an association between 30-day mortality and serum concentrations of caspase- 3 on days 1 ( $p<0.001), 4$ $(\mathrm{p}<0.001)$ and $8(\mathrm{p}<0.001)$ controlling for SOFA and age.
Fig. 1 Serum caspase-3 concentrations on days 1,4 and 8 in non-survivor and survivor patients

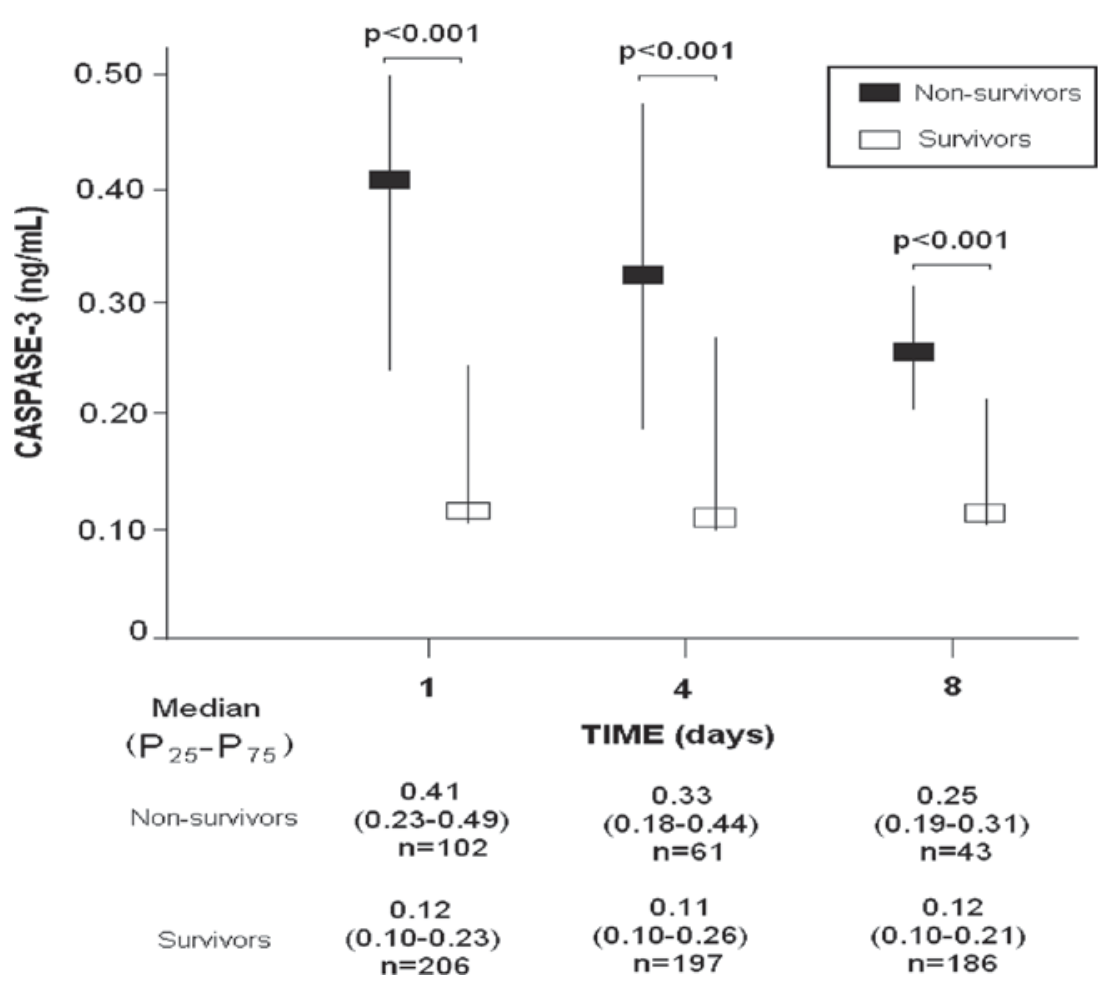


Table 3 Receiver operation characteristic analysis using serum concentrations of caspase3 at day 1, 4 and 8 as predictor of mortality at 30 days

\begin{tabular}{llll}
\hline Measure & Day 1 & Day 4 & Day 8 \\
\hline Cut-off of serum caspase-3 levels & $>0.22 \mathrm{ng} / \mathrm{mL}$ & $>0.16 \mathrm{ng} / \mathrm{mL}$ & $>0.14 \mathrm{ng} / \mathrm{mL}$ \\
Sensitivity (95\% CI) & $78(69-86)$ & $85(74-93)$ & $93(81-98)$ \\
Specificity (95\% CI) & $74(68-80)$ & $62(55-69)$ & $61(53-68)$ \\
Positive likelihood ratio (95\% CI) & $3.1(2.4-3.9)$ & $2.3(1.8-2.8)$ & $2.4(1.9-2.9)$ \\
Negative likelihood ratio (95\% CI) & $0.3(0.2-0.4)$ & $0.2(0.1-0.4)$ & $0.2(0.1-0.3)$ \\
Positive predicted value $(95 \% \mathrm{CI})$ & $60(51-69)$ & $41(33-50)$ & $35(27-45)$ \\
Negative predicted value $(95 \% \mathrm{CI})$ & $87(82-92)$ & $93(87-97)$ & $97(93-99)$ \\
\hline
\end{tabular}

CI confidence intervals
Kaplan-Meier 30-day survival curves with cut-off values of serum concentrations of caspase- 3 at days 1, 4 and 8 are shown in Fig. 3. We found that patients with higher serum concentrations of caspase- 3 on days 1 ( $p<0.001), 4$ $(\mathrm{p}<0.001)$ and $8(\mathrm{p}<0.001)$ had higher risk of death.

\section{Discussion}

The new findings of this work were that an association between serum caspase- 3 concentrations during the first week, apoptosis degree, sepsis severity, and sepsis mortality exists.

Previously, higher caspase-3 activity in lymphocytes of septic patients compared to healthy controls [19-21], in spleens of septic patients compared to non-septic patients [22], in plasma of septic patients compared to non-septic patients [23], and in serum of septic patients with decreased lactate clearance [24] have been found. In addition, we previously found higher serum caspase- 3 concentrations at time of severe sepsis diagnosis in 30-day non-survivors than in survivor patients, and an association between serum caspase- 3 concentrations at severe sepsis diagnosis and 30-day mortality
[25]. Thus, new findings of this work were that 30-day nonsurvivors had higher serum caspase- 3 concentrations during the first week than survivor patients, and that there is an association between serum caspase- 3 concentrations during the first week and 30-day mortality.

We found in our previous study that serum caspase- 3 levels at severe sepsis diagnosis could be used as 30-day sepsis mortality prediction biomarker [25]. Thus, another new finding of this study was that serum caspase- 3 levels on days 4 and 8 of severe sepsis diagnosis also could be used as a 30-day sepsis mortality prediction biomarker according to the results of receiver operating characteristic analysis.

In our previous study, we found that an association between serum concentrations of caspase- 3 (as the main executor of apoptosis) and CCCK-18 levels (as biomarker of degree of apoptosis) at the moment of severe sepsis diagnosis exists [25]. Then, another interesting and new finding of this work is the association between serum concentrations of caspase- 3 and CCCK-18 during the first week.

Another new finding of this work was that an association between serum concentrations of caspase-3 during the first week and sepsis severity (assess by serum concentration of acid lactic and SOFA score) exists.
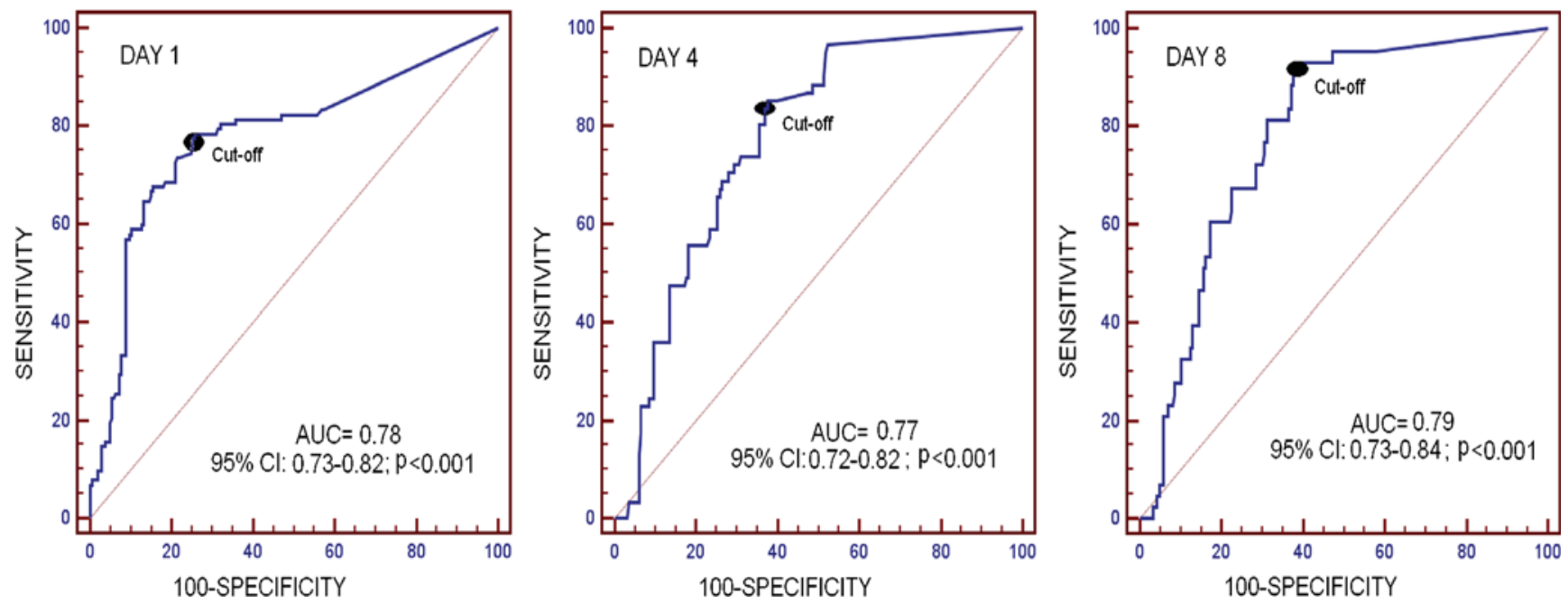

Fig. 2 Receiver operation characteristic curves of serum caspase-3 levels on days 1, 4 and 8 to predict 30-day mortality 
Table 4 Multiple logistic regression analyses to predict mortality at 30 days

\begin{tabular}{llll}
\hline Measure & Odds ratio & $95 \%$ confidence interval & p-value \\
\hline Model: Mortality estimated at day 1 & & & \\
$\quad$ Caspase-3 levels $>0.22 \mathrm{ng} / \mathrm{mL}$ on day 1 & 9.420 & $5.229-16.972$ & $<0.001$ \\
SOFA at day 1 & 1.171 & $1.079-1.270$ & $<0.001$ \\
Age (years) & 1.022 & $1.001-1.043$ & 0.04 \\
Model: Mortality estimated at day 4 & & & $<0.001$ \\
$\quad$ Caspase-3 levels $>0.16 \mathrm{ng} / \mathrm{mL}$ on day 4 & 8.274 & $3.615-18.940$ & $<0.001$ \\
SOFA at day 4 & 1.187 & $1.092-1.290$ & 0.14 \\
Age (years) & 1.019 & $0.994-1.045$ & $<0.001$ \\
Model: Mortality estimated at day 8 & & & $<0.001$ \\
Caspase-3 levels $>0.14 \mathrm{ng} / \mathrm{mL}$ on day 8 & 15.661 & $4.519-54.276$ & 0.09 \\
SOFA at day 8 & 1.189 & $1.084-1.304$ & $0.996-1.056$ \\
Age (years) & 1.025 & & \\
\hline
\end{tabular}

SOFA sepsis-related organ failure assessment
There are mainly two different pathways of cell death by apoptosis: the mitochondrial (or intrinsic) pathway and the death receptor (or extrinsic) pathway [3-6]. The intrinsic pathway could be initiated by reactive oxygen species or by cytokines as interleukin (IL)-1 and IL-6, and could be slowed by IL-10 (through to the activation of Bcl-2 anti-apoptotic family); and afterwards, cytochrome c is released from mitochondria and caspase 3 is activated. The extrinsic pathway is initiated when the TNF ligand superfamily (TNFSF) binds to the TNF membrane receptors superfamily (TNFRSF), such as FasL (Apo-1 L or TNFSF-6 or CD95L) binding to Fas (Apo-1 or TNFRSF-6 or CD95) or TNF-related apoptosisinducing ligand (TNFSF-10 or TRAIL) binding to its different receptors (TNFRSF-10A to D or TRAILR1 to 4); afterwards, a death signal is generated to cleave pro-caspase- 8 generating caspase- 8 that activates caspase-3. After the activation of caspase-3, by either of two pathways, the cell death is initiated. Cytokeratin-18 protein, that is present in most parenchymal and epithelial cells, could cleave during apoptosis by caspases and its CCCK-18 fragments appear afterward in the blood [37, 38]. Thus, we think that the association that we found in our work between serum concentrations of caspase-3 during the first week and sepsis mortality could reflect that patients with higher caspase-3 (main apoptosis executor) have higher degree of apoptosis (with higher serum CCCK-18 concentrations), higher sepsis severity (with higher SOFA score and higher serum acid lactic concentrations) and sepsis mortality.

In an animal model with septic rats, the caspase inhibitors administration have reduced apoptosis and mortality rates [7-9]; thus, all those findings could stimulate interest for research about agents that modulate caspase- 3 activation in those patients.

Certain limitations exist in our work, for example, we have not determined other molecules related to apoptosis activation, such as Fas, FasL, and Bcl-2. Besides, we have not determined the degree of apoptosis by other methods, such as annexin- $\mathrm{V}$ to assess membrane alterations or terminal deoxynucleotidyl transferase dUTP nick end labeling (TUNEL) to assess DNA fragmentation.
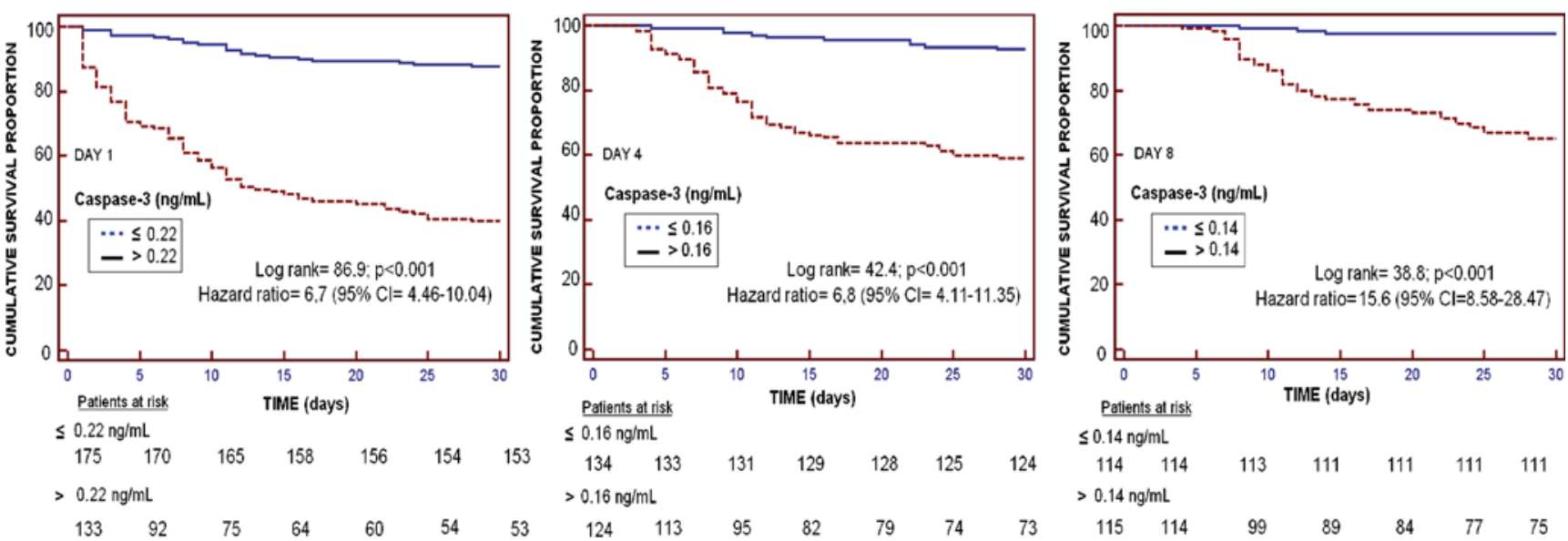

Fig. 3 Kaplan-Meier 30-day survival curves of serum caspase-3 concentrations on days 1, 4 and 8 


\section{Conclusions}

The new findings of this work were that an association between serum caspase- 3 concentrations during the first week, apoptosis degree, sepsis severity, and sepsis mortality exists. Thus, serum caspase- 3 concentration determination could be proposed to estimate the prognosis of those patients, and could open the interest for research about agents that modulate caspase- 3 activation in those patients.

Acknowledgments This study was supported by grants from Instituto de Salud Carlos III (PI14/00220 and INT16/00165) (Madrid, Spain) and co-financed by Fondo Europeo de Desarrollo Regional (FEDER). The funders had no role in study design, data collection and analysis, decision to publish, or preparation of the manuscript.

Author contributions LLo conceived, designed and coordinated the study, participated in acquisition and interpretation of data, and drafted the manuscript.

MMM, ROL, JF, JSV, LLa, CD, SP participated in acquisition of data.

APC and AFGR participated in determination of serum concentrations.

AJ participated in the interpretation of data.

All authors revised the manuscript critically for important intellectual content and made the final approval of the version to be published.

\section{Compliance with ethical standards}

Conflict of interest The authors declare that they have no competing interests.

Ethical approval The study was approved by the research Ethics Committee of each hospital: H General de La Palma (La Palma), HU Insular (Las Palmas de Gran Canaria), H Quirón (Santa Cruz de Tenerife), HU de Valencia (Valencia), HU de Canarias (La Laguna), H San Jorge (Huesca), HU Dr. Negrín (Las Palmas de Gran Canaria), and HU Nuestra Señora de Candelaria (Santa Cruz de Tenerife).

Informed consent Patients or family members signed the informed consent to participate in the study.

Abbreviations $A P A C H E$, Acute physiology and chronic health evaluation; $a P T T$, Activated partial thromboplastin time; $\mathrm{COPD}$, Chronic obstructive pulmonary disease; $\mathrm{FIO}_{2}$, Fraction inspired oxygen; INR, International normalized ratio; $I C U$, Intensive care unit; $\mathrm{PaO}_{2}$, Pressure of arterial oxygen; TNF, Tumor necrosis factor; SOFA, Sepsis-related organ failure assessment score

\section{References}

1. Vincent JL, Sakr Y, Sprung CL, Ranieri VM, Reinhart K, Gerlach H, Moreno R, Carlet J, Le Gall JR, Payen D, Sepsis occurrence in acutely ill patients investigators (2006) Sepsis in European intensive care units: results of the SOAP study. Crit Care Med 34:344353

2. Angus DC, Linde-Zwirble WT, Lidicker J, Clermont G, Carcillo J, Pinsky MR (2001) Epidemiology of severe sepsis in the United
States: analysis of incidence, outcome, and associated costs of care. Crit Care Med 29:1303-1310

3. Fischer U, Schulze-Osthoff K (2005) Apoptosis-based therapies and drug targets. Cell Death Differ 12:942-961

4. Wesche-Soldato DE, Swan RZ, Chung CS, Ayala A (2007) The apoptotic pathway as a therapeutic target in sepsis. Curr Drug Targets 8:493-500

5. Huttunen R, Aittoniemi J (2011) New concepts in the pathogenesis, diagnosis and treatment of bacteremia and sepsis. J Inf Secur 63: 407-419

6. Harjai M, Bogra J, Kohli M, Pant AB (2013) Is suppression of apoptosis a new therapeutic target in sepsis? Anaesth Intensive Care 41:175-183

7. Hotchkiss RS, Chang KC, Swanson PE, Tinsley KW, Hui JJ, Klender P, Xanthoudakis S, Roy S, Black C, Grimm E, Aspiotis R, Han Y, Nicholson DW, Karl IE (2000) Caspase inhibitors improve survival in sepsis: a critical role of the lymphocyte. Nat Immunol 1:496-501

8. Matsuda N, Teramae H, Futatsugi M, Takano K, Yamamoto S, Tomita K, Suzuki T, Yokoo H, Koike K, Hattori Y (2010) Upregulation of histamine $\mathrm{H} 4$ receptors contributes to splenic apoptosis in septic mice: counteraction of the antiapoptotic action of nuclear factor-kappaB. J Pharmacol Exp Ther 332:730-737

9. Li P, Bledsoe G, Yang ZR, Fan H, Chao L, Chao J (2014) Human kallistatin administration reduces organ injury and improves survival in a mouse model of polymicrobial sepsis. Immunology 142: 216-226

10. Supinski GS, Callahan LA (2014) ß-hydroxy- $\beta$-methylbutyrate (HMB) prevents sepsis-induced diaphragm dysfunction in mice. Respir Physiol Neurobiol 196:63-68

11. Ali I, Nanchal R, Husnain F, Audi S, Konduri GG, Densmore JC, Medhora M, Jacobs ER (2013) Hypoxia preconditioning increases survival and decreases expression of toll-like receptor 4 in pulmonary artery endothelial cells exposed to lipopolysaccharide. Pulm Circ 3:578-588

12. Stoyanoff TR, Todaro JS, Aguirre MV, Zimmermann MC, Brandan NC (2014) Amelioration of lipopolysaccharide-induced acute kidney injury by erythropoietin: involvement of mitochondriaregulated apoptosis. Toxicology 318:13-21

13. Inoue $\mathrm{S}$, Sato $\mathrm{T}$, Suzuki-Utsunomiya K, Komori Y, Hozumi K, Chiba T, Yahata T, Nakai K, Inokuchi S (2013) Sepsis-induced hypercytokinemia and lymphocyte apoptosis in aging-accelerated Klotho knockout mice. Shock 39:311-316

14. Xie K, Yu Y, Huang Y, Zheng L, Li J, Chen H, Han H, Hou L, Gong G, Wang G (2012) Molecular hydrogen ameliorates lipopolysaccharide-induced acute lung injury in mice through reducing inflammation and apoptosis. Shock 37:548-555

15. Shinozaki S, Inoue Y, Yang W, Fukaya M, Carter EA, Yu YM, Fischman A, Tompkins R, Kaneki M (2010) Farnesyltransferase inhibitor improved survival following endotoxin challenge in mice. Biochem Biophys Res Commun 391:1459-1464

16. Supinski GS, Wang W, Callahan LA (2009) Caspase and calpain activation both contribute to sepsis-induced diaphragmatic weakness. J Appl Physiol 107:1389-1396

17. Matsuda N, Takano Y, Kageyama S, Hatakeyama N, Shakunaga K, Kitajima I, Yamazaki M, Hattori Y (2007) Silencing of caspase-8 and caspase-3 by RNA interference prevents vascular endothelial cell injury in mice with endotoxic shock. Cardiovasc Res 76:132140

18. Ozdulger A, Cinel I, Koksel O, Cinel L, Avlan D, Unlu A, Okcu H, Dikmengil M, Oral U (2003) The protective effect of Nacetylcysteine on apoptotic lung injury in cecal ligation and puncture-induced sepsis model. Shock 19:366-372

19. Zhang Y, Li J, Lou J, Zhou Y, Bo L, Zhu J, Zhu K, Wan X, Cai Z, Deng X (2011) Upregulation of programmed death-1 on T cells and 
programmed death ligand-1 on monocytes in septic shock patients. Crit Care 15:R70

20. Delogu G, Famularo G, Tellan G, Marandola M, Antonucci A, Signore M, Marcellini S, Moretti S (2008) Lymphocyte apoptosis, caspase activation and inflammatory response in septic shock. Infection 36:485-487

21. Weber SU, Schewe JC, Lehmann LE, Müller S, Book M, Klaschik S, Hoeft A, Stüber F (2008) Induction of Bim and bid gene expression during accelerated apoptosis in severe sepsis. Crit Care 12: R128

22. Hotchkiss RS, Swanson PE, Freeman BD, Tinsley KW, Cobb JP, Matuschak GM, Buchman TG, Karl IE (1999) Apoptotic cell death in patients with sepsis, shock, and multiple organ dysfunction. Crit Care Med 27:1230-1251

23. Clementi A, Virzì GM, Brocca A, Pastori S, de Cal M, Marcante S, Granata A, Ronco C (2016) The role of cell-free plasma DNA in critically ill patients with sepsis. Blood Purif 41:34-40

24. Nguyen HB, Loomba M, Yang JJ, Jacobsen G, Shah K, Otero RM, Suarez A, Parekh H, Jaehne A, Rivers EP (2010) Early lactate clearance is associated with biomarkers of inflammation, coagulation, apoptosis, organ dysfunction and mortality in severe sepsis and septic shock. J Inflamm (Lond) 7:6

25. Lorente L, Martín MM, Ferreres J, Solé-Violán J, Labarta L, Díaz C, Jiménez A, Borreguero-León JM (2016) Serum caspase 3 levels are associated with early mortality in severe septic patients. J Crit Care 34:103-106

26. Levy MM, Fink MP, Marshall JC, Abraham E, Angus D, Cook D, Cohen J, Opal SM, Vincent JL, Ramsay G, International Sepsis Definitions Conference (2003) 2001 SCCM/ESICM/ACCP/ATS/ SIS international sepsis definitions conference. Intensive Care Med 29:530-538

27. Lorente L, Martín MM, Pérez-Cejas A, López RO, Ferreres J, SoléViolán J, Labarta L, Díaz C, Palmero S, Buitrago M, Jiménez A, Borreguero-León JM (2017) Higher serum caspase-cleaved cytokeratin-18 levels during the first week of sepsis diagnosis in non-survivor patients. Clin Chem Lab Med 55(10):1621-1629

28. Lorente L, Martín MM, Abreu-González P, Domínguez-Rodriguez A, Labarta L, Díaz C, Solé-Violán J, Ferreres J, Cabrera J, Igeño JC, Jiménez A (2013) Sustained high serum malondialdehyde levels are associated with severity and mortality in septic patients. Crit Care $17: R 290$
29. Lorente L, Martín MM, Solé-Violán J, Blanquer J, Labarta L, Díaz C, Borreguero-León JM, Orbe J, Rodríguez JA, Jiménez A, Páramo JA (2014) Association of sepsis-related mortality with early increase of TIMP-1/MMP-9 ratio. PLoS One 9:e94318

30. Lorente L, Martín MM, López-Gallardo E, Blanquer J, Solé-Violán J, Labarta L, Díaz C, Jiménez A, Montoya J, Ruiz-Pesini E (2015) Decrease of oxidative phosphorylation system function in severe septic patients. J Crit Care 30:935-939

31. Lorente L, Martín MM, Pérez-Cejas A, Ferreres J, Solé-Violán J, Labarta L, Díaz C, Jiménez A (2017) Non-survivor septic patients have persistently higher serum SCD40L levels than survivors. J Crit Care 41:177-182

32. Knaus WA, Draper EA, Wagner DP, Zimmerman JE (1985) APACHE II: a severity of disease classification system. Crit Care Med 13:818-829

33. Vincent JL, Moreno R, Takala J, Willatts S, De Mendonça A, Bruining H, Reinhart CK, Suter PM, Thijs LG, for the Working Group on Sepsis-related Problems of the European Society of Intensive Care Medicine (1996) The sepsis-related organ failure assessment (SOFA) score to describe organ dysfunction/failure. Intensive Care Med 22:707-710

34. Roth GA, Krenn C, Brunner M, Moser B, Ploder M, Spittler A, Pelinka L, Sautner T, Wolner E, Boltz-Nitulescu G, Ankersmit HJ (2004) Elevated serum levels of epithelial cell apoptosis-specific cytokeratin 18 neoepitope $\mathrm{m} 30$ in critically ill patients. Shock 22 : 218-220

35. Moore DJ, Greystoke A, Butt F, Wurthner J, Growcott J, Hughes A, Dive C (2012) A pilot study assessing the prognostic value of CK18 and nDNA biomarkers in severe sepsis patients. Clin Drug Investig 32:179-187

36. Hofer S, Brenner T, Bopp C, Steppan J, Lichtenstern C, Weitz J, Bruckner T, Martin E, Hoffmann U, Weigand MA (2009) Cell death serum biomarkers are early predictors for survival in severe septic patients with hepatic dysfunction. Crit Care 13:R93

37. Chu PG, Weiss LM (2002) Keratin expression in human tissues and neoplasms. Histopathology 40:403-439

38. Caulín C, Salvesen GS, Oshima RG (1997) Caspase cleavage of keratin 18 and reorganization of intermediate filaments during epithelial cell apoptosis. J Cell Biol 138:1379-1394 